\title{
An Investigation of Recovery Mechanisms for Oil Field Optimization by Three-Phase Core Flood and Simulation Studies
}

\author{
C. Jones ${ }^{1, *}, J$. Brodie ${ }^{1}, M$. Spearing ${ }^{1}, S$. Lamb $^{1}, K$. Sadikoglu ${ }^{1}$
}

1BP, Sunbury on Thames, United Kingdom

\begin{abstract}
Two potential recovery mechanisms are being considered for a major field which required laboratory measurements to investigate the efficiency of the two scenarios: gas flood followed by water flood and water flood followed by gas flood. Although simply stated, the recovery scenarios involved complex threephase processes which had to be replicated in the laboratory at reservoir conditions to provide reliable data upon which reservoir development decisions could be made. The first sequence consisted of water displacing oil to residual oil saturation (Sorw), oil displacing water to residual water saturation (Swro) and gas displacing both oil and water to Sor $3 \phi$,g and Swr3 $\phi$,g. The second sequence consisted of gas displacing oil to residual oil saturation (Sorg), oil displacing gas to trapped gas saturation (Sgto) and water displacing both oil and gas to Sor $3 \phi, w$ and Sgt3 $\phi, w$ respectively. Composite cores of four well-matched plugs at Swi were used and all measurements were made at bubble point conditions. A vertical core holder was housed inside a reservoir condition facility equipped with gamma attenuation saturation monitoring (GASM). Temperature stability and the use of GASM were paramount for the accurate measurement of produced fluids, especially trapped gas saturation. Oil, gas and water produced volumes were also measured using a separator housed inside the core flood oven to provide optimum temperature stability. The laboratory results were modelled in a compositional simulator using an equation of state tuned to conventional PVT data and both swelling and multiple contact experiments. The objective was to build a three-phase predictive model from the constituent two-phase relative permeability data. The paper details the experimental methods and presents results for each section of the two sequences. The key conclusions are that Sorg $>$ Sorw $>$ Sor $3 \phi, g>$ Sor $3 \phi, w$ and Sgt $3 \phi, w<$ Sgto.
\end{abstract}

\section{Introduction}

Current field operations include both water injection and gas injection. The purpose of the two coreflood sequences described in this paper is to compare oil recovery achieved through crestal equilibrium gas injection (i.e. an immiscible gravity drainage flood) followed by down-dip water injection to a double displacement process, where water injection is followed by crestal equilibrium gas flood into the water-swept zone [1], [2]. All plugs used in the study were of the same rock type, a moderately well sorted, fine-grained sandstone with a massive texture. They were poorly cemented and contained small amounts of detrital clay which introduced some microporosity. Individual plug porosities varied from 22 to $25 \%$ and had absolute permeabilities to brine of between $288 \mathrm{mD}$ and $411 \mathrm{mD}$. Mercury injection samples from a number of plugs used in the tests suggested a largely unimodal distribution of pore throat diameters of $20-25 \mu \mathrm{m}$.

\section{Experimental Procedures}

\subsection{Coreflood 1}

The first coreflood sequence was designed to simulate a "double displacement" process starting with a waterflood upwards through the composite at $4 \mathrm{ml} / \mathrm{h}$ to Sorw. The rate was chosen as it represented a realistic frontal advance rate for the field. For practical purposes, the waterflood was stopped when oil cut had fallen to $<0.1 \%$. Sorw was measured by brine dispersion. The waterflood was followed by an oil flood downwards at $4 \mathrm{ml} / \mathrm{h}$, which simulated an oil bank being driven into the water flooded zone by gas flood (secondary drainage) to Swro. The final flood in the sequence, an equilibrium gas flood downwards, simulated expansion of the

* Corresponding author: Christopher.Jones2@uk.bp.com

(C) The Authors, published by EDP Sciences. This is an open access article distributed under the terms of the Creative Commons Attribution License 4.0 (http://creativecommons.org/licenses/by/4.0/). 
gas cap into the oil zone, driving the oil saturation to Sor3 $\phi, g$ and Swr3 $\phi, g$. The flood continued at $4 \mathrm{ml} / \mathrm{h}$ until a $99.9 \%$ gas cut, after which the flood rate was increased to $400 \mathrm{ml} / \mathrm{h}$ to remove capillary-retained fluids at the outlet end. The three flood sequences are depicted below in Figure 1. The residual saturation relevant to the lab test measured at the end of the sequence of floods are highlighted in red in Figure 1. After the floods were complete, the composite was solvent cleaned in-situ and $100 \%$ saturation GASM calibrations were performed for each of the three test fluids, followed by a total pore volume measurement by miscible dispersion.

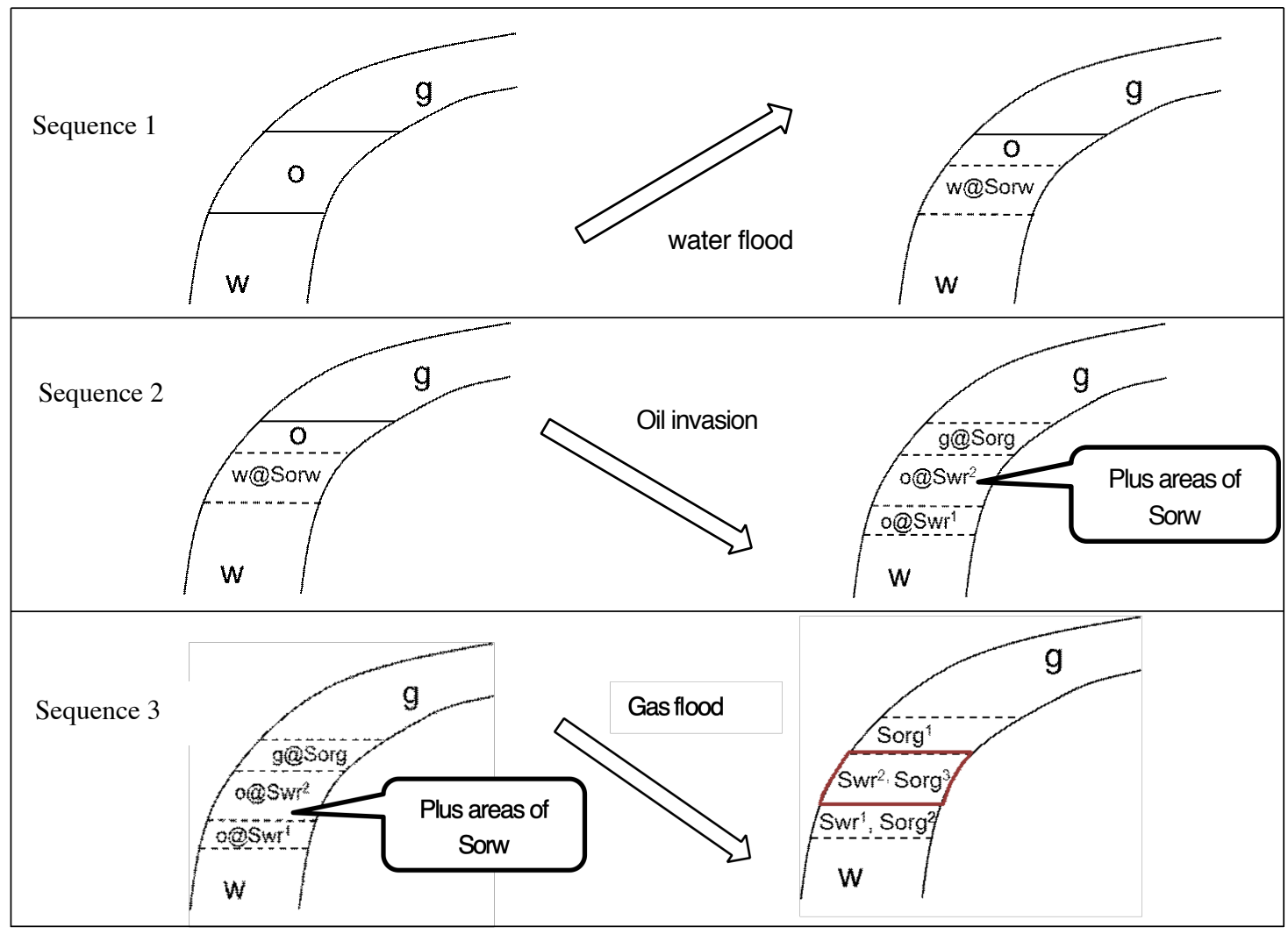

Figure 1. Coreflood 1 flood sequences

\subsection{Coreflood 2}

The second coreflood sequence effectively reversed the sequence described for Coreflood 1. Coreflood 2 started with an equilibrium gas flood vertically downwards, followed by a secondary oil flood upwards and finally a waterflood upwards. The gas flood was designed to simulate crestal gas injection, resulting in an equilibrium gas drive and gravity drainage of oil. The flood rate was initially $4 \mathrm{ml} / \mathrm{h}$, representative of the frontal advance rate in the field and was continued until the oil cut had reduced to < $0.1 \%$. At this point, the flood rate was increased to $400 \mathrm{ml} / \mathrm{h}$ until c. 47 pore volume (PV) of equilibrium gas had been injected and the oil cut was $<0.1 \%$. The intermediate oil flood simulates down dip water injection, which drives oil into the gas-swept zone, trapping gas. The flood rate was $4 \mathrm{ml} / \mathrm{h}$ and was continued until oil had just broken through at the outlet (top) face of the composite. The final sequence, a tertiary waterflood, then simulates the advance of the water flood into this zone, and drives the oil saturation down to residual oil saturation at trapped gas, Sor $3 \phi, w$. Again, the flood rate was 4 $\mathrm{ml} / \mathrm{h}$ and continued until water cut was $>99.9 \%$. The flood rate was then increased to $40 \mathrm{ml} / \mathrm{h}$ to remove capillary trapped fluids at the outlet of the core. A miscible brine dispersion was done to measure the aqueous pore volume. The red highlighted region in Figure 2 represents the residual saturations at the end of the coreflood sequence. Pure phase GASM calibrations and 
total pore volume were measured as for

Coreflood 1.

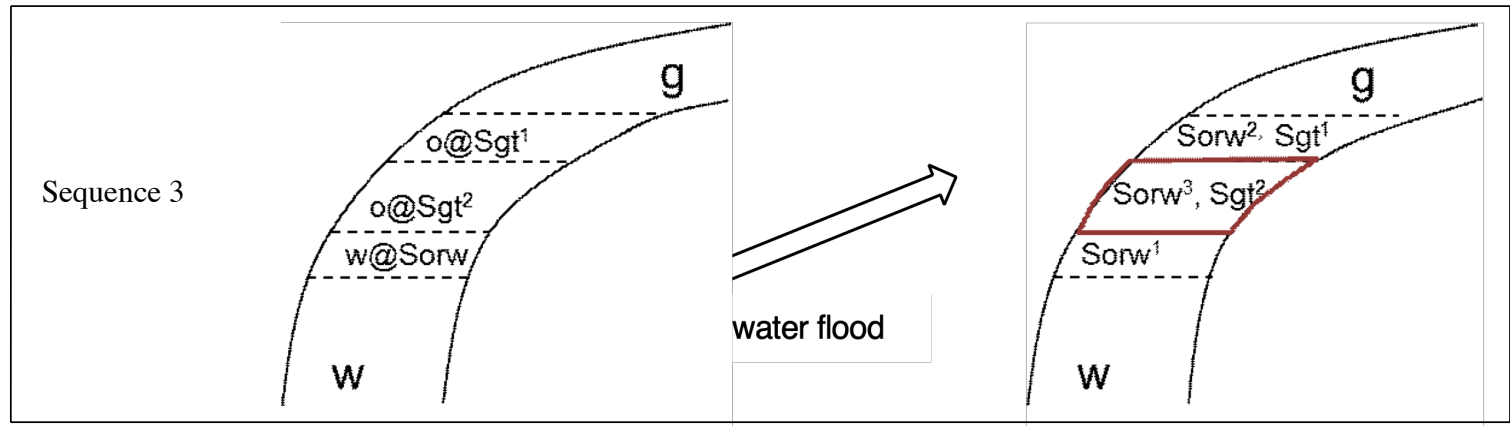

Figure 2. Coreflood 2 final flood sequence

\subsection{Fluid Preparation}

A sample of stock tank oil was combined with a synthetic hydrocarbon gas mixture to produce an initial live crude oil (LCO) which matched the composition of the reservoir fluid at reservoir bubble point conditions of $71^{\circ} \mathrm{C}$ and 3890 psig. Equilibrium gas was produced by flashing a small subsample of the LCO to 3850 psig at $71^{\circ} \mathrm{C}$ (i.e. 40 psi below bubble point) and allowing an equilibrium gas phase to evolve. This gas phase was removed and analysed to provide an approximation of the equilibrium gas at reservoir conditions. A large volume of this approximated equilibrium gas was produced from pure components and contacted with an equal volume of the LCO in a PVT vessel. This was done for an extended period of time at reservoir (bubble point) conditions to ensure true equilibrium between the fluids was reached. The final gas and oil phases were then separated and used during the coreflood tests as true equilibrium fluids. Synthetic brines were used matching the ionic composition of the formation brine and enlivened using the equilibrium gas described above, sodium iodide was used to increase the accuracy of the GASM data.

\subsection{Coreflood Rig Design}

A series of sister plugs, of matched permeability and porosity, were prepared to Swi with doped brine $(5 \% \mathrm{NaI})$ using the confined porous plate technique. A composite of four plugs was constructed for each coreflood and wrapped in a layer of gas-impermeable aluminium shim and a liquid-impermeable Viton rubber sleeve. At the start of each coreflood, the composite was loaded into a vertically-orientated carbon fibre core holder. The vertical orientation allowed gravity stable displacements to be performed (e.g. less dense gas is injected at the top of the core, water is injected at the base). Hydrostatic overburden pressure was provided by de-ionised water with a Enerpac pump supported by a large volume gas buffer. Pressure was logged throughout the experimental sequence. The core holder, piston vessels containing all live experimental fluids, in-situ saturation monitoring detectors and the visual separator equipment were contained inside an oven to ensure temperature stability. Gamma ray sources were mounted outside the oven, close to the core holder and detectors inside the oven. The GASM system allowed fluid saturations within the composite core to be monitored qualitatively throughout the corefloods and quantitatively at the end of the floods, once $100 \%$ phase calibrations had been completed. Effluent from all flood sequences was piped into a visual separator, which was mounted inside the core flood rig oven to ensure temperature and pressure equilibrium with the core. The separator allowed the production of two phases to be measured by a camera system mounted outside the oven. Meniscus heights, and hence volumetric production, were monitored throughout the floods. The coreflood rig layout is summarized in Figure 3. 


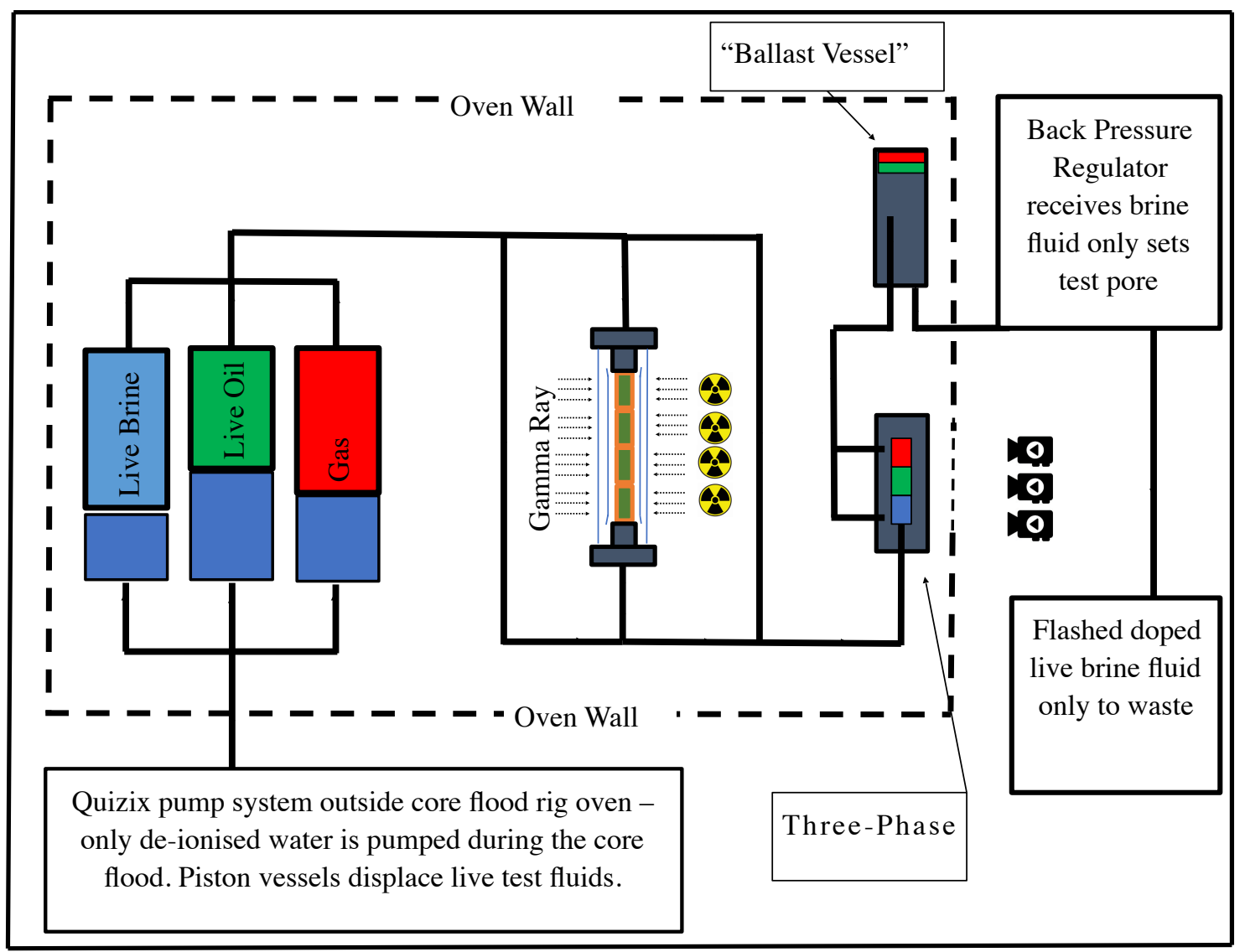

Figure 3. Schematic of coreflood rig design

All live fluids for the tests were contained inside titanium or Hastelloy piston vessels inside the rig oven and driven by a Quizix pump system. Before loading into the oven, LCO samples were taken to reservoir conditions inside a PVT vessel and a bubble point check was performed using the Quizix pump. The outlet BPR pressure was set at precisely the $\mathrm{Pb}$ of the LCO, and the setpoint was tested using the same Quizix pump. Once loaded into the coreflood rig, the composites were brought to reservoir conditions with hydrostatic overburden of 7310 psig. The composites were thoroughly degassed before a hydrocarbon pore volume measurement was made by miscible dispersion of kerosene with a second kerosene phase doped with 1iodododecane. Composites were then saturated with LCO, which was refreshed weekly during a total ageing period of three weeks. Both coreflood sequences therefore started with the aged composites saturated in LCO at Swi.

\section{Analysis of Results}

\subsection{In Situ Saturation Monitoring}

Twelve GASM source/detector pairs were positioned along the length of the composites, three detectors per plug. The detectors recorded the log of the count rate (LCR) over a 1-minute period. Changes in LCR during the test can be attributed to changes in fluid attenuation only [3]. $100 \%$ phase saturation calibrations were carried out at the end of the corefloods to allow conversion of LCR to phase saturations. If Io, Ig and Iw represent the LCR at each detector for $100 \%$ saturations of LCO, equilibrium gas and doped brine respectively, the contribution to LCR from these phases recorded at each detector during the core flood, I, is given by:

$$
I=S_{o} I_{o}+S_{g} I_{g}+S_{w} I_{w}
$$

If only two phases are present, the LCR is readily converted to phase saturation. For example, for two-phase oil and water:

$$
\mathrm{S}_{w}=\frac{I-I_{o}}{I_{w}-I_{o}}
$$


This equation applies to the secondary water flood and equilibrium oil flood in Coreflood 1. If three phases are present, one of which is stationary, for example water at Swi, LCR can be converted to saturation provided the initial count rate at Swi is measured (ISwi) prior to the start of the core flood. This is true for the secondary equilibrium gas flood and subsequent oil flood in Coreflood 2:

$$
\begin{aligned}
\mathrm{S}_{w i} & =\frac{I_{S w i}-I_{o}}{I_{w}-I_{o}} \\
\mathrm{~S}_{g} & =\frac{I-I_{o}\left(1-S_{w i}\right)-S_{w i} I_{w}}{I_{g}-I_{o}} \\
S_{o} & =1-S_{g}-S_{w i}
\end{aligned}
$$

During the tertiary equilibrium gas flood in Coreflood 1, no water was produced during the low-rate flood, so a version of equation (4) can be used which uses LCR at Swr at the end of the preceding oil flood instead of LCR at Swi:

$$
\mathrm{S}_{g}=\frac{I-I_{o}\left(1-S_{w r}\right)-S_{w r} I_{w}}{I_{g}-I_{o}}
$$

Equations (1) to (6) provide quantitative saturation data for all floods described in this paper apart from the tertiary water flood in Coreflood 2, where three phases are mobile prior to water breakthrough. However, in that case it is possible to provide quantitative saturation data at the end of the tertiary waterflood based on the assumption that gas mobilised by the waterflood is de-trapped uniformly along the length of the composite. At the end of the equilibrium oil flood and immediately prior to the tertiary water flood all saturations are known; trapped gas saturation $\mathrm{Sgt}, \mathrm{Sw}(=\mathrm{Swi})$ and $\mathrm{So}=1-\mathrm{Sgt}-$ Swi. Isgt is the count rate recorded at this point. Substituting into equation (1) and rearranging gives:

$$
\mathrm{S}_{g t}=\frac{\left(I_{S g t}-I_{o}\right)-S_{w i}\left(I_{w}-I_{o}\right)}{I_{g}-I_{o}}
$$

As the water front moves through the composite it de-traps gas, and the volume of de-trapped gas is measured in the separator. The value of trapped gas saturation at each detector, Sgt ( $t$ ), can therefore be constrained using the separator gas production, assuming uniform de-trapping along the length of the composite. Substituting $\mathrm{Sw}=1-$ So - Sgt (t)into equation (1) and rearranging gives:

$$
\mathrm{S}_{o}=\frac{\left(I-I_{w}\right)-S_{g t}(t)\left(I_{g}-I_{w}\right)}{I_{o}-I_{w}}
$$

Clearly, whilst the water front is moving through the composite, the assumption of uniform detrapping along its length is not valid since gas will only de-trap behind the water front. However, very little de-trapping occurs after water breakthrough, and after this point, Equation (8) allows phase saturations to be

\begin{tabular}{|c|c|c|c|c|c|}
\hline Flood 1 & \multicolumn{2}{|c|}{ Waterflood } & Equilibrium Oil Flood & \multicolumn{2}{|c|}{ Equilibrium Gas flood } \\
\hline Swi (frac PV) & \multicolumn{5}{|c|}{0.128} \\
\hline PV Injected & \multicolumn{2}{|c|}{18} & 8 & \multicolumn{2}{|c|}{22} \\
\hline $\begin{array}{c}\text { Flood } \\
\text { Sequence }\end{array}$ & $\begin{array}{c}\text { Secondary } \\
\text { Water Flood } \\
\text { Ros (frac PV) }\end{array}$ & $\begin{array}{c}\text { Eps water } \\
\text { flood }\end{array}$ & $\begin{array}{c}\text { Oil Flood Secondary } \\
\text { Drainage Swro (frac } \\
\text { PV) }\end{array}$ & $\begin{array}{c}\text { Tertiary Gas } \\
\text { Flood Sor } 3 \phi, g \\
(\text { frac PV) }\end{array}$ & $\begin{array}{c}\text { Eps tertiary } \\
\text { gas flood at } \\
\text { Swr }\end{array}$ \\
\hline $\begin{array}{l}\text { GASM } \\
\text { Separator }\end{array}$ & $\begin{array}{l}0.26 \\
0.29\end{array}$ & $70 \%$ & $\begin{array}{l}0.31 \\
0.29\end{array}$ & $\begin{array}{l}0.17 \\
0.20\end{array}$ & $81 \%$ \\
\hline
\end{tabular}
estimated.

\subsection{Coreflood 1 Results}

Results for Coreflood 1 are summarized in Table 1 :

Table 1. Summary of results for Coreflood 1

The secondary water flood commenced after a three week ageing period using LCO at Swi at reservoir conditions. After $18 \mathrm{PV}$ throughput at 4 $\mathrm{ml} / \mathrm{h}$, the average remaining oil saturation (ROS) was 0.26 or $0.29 \mathrm{PV}$ based on GASM or separator data respectively, indicating a pore scale displacement efficiency $($ Eps $=(1-$ SorSwi)/(1-Swi)) of $70 \%$. No high rate "bump flood" was performed and GASM saturation profiles suggested some capillary retention of 
LCO at the core outlet. Saturations far from the outlet of the plug, and data from a series of other corefloods on similar plugs where bump floods were done suggest a Sorw is c. 0.21 PV. A brine dispersion towards the end of the water flood constrained the water saturation to be close to the GASM value. Average phase saturations during Coreflood 1 are shown in Figure 4, below.

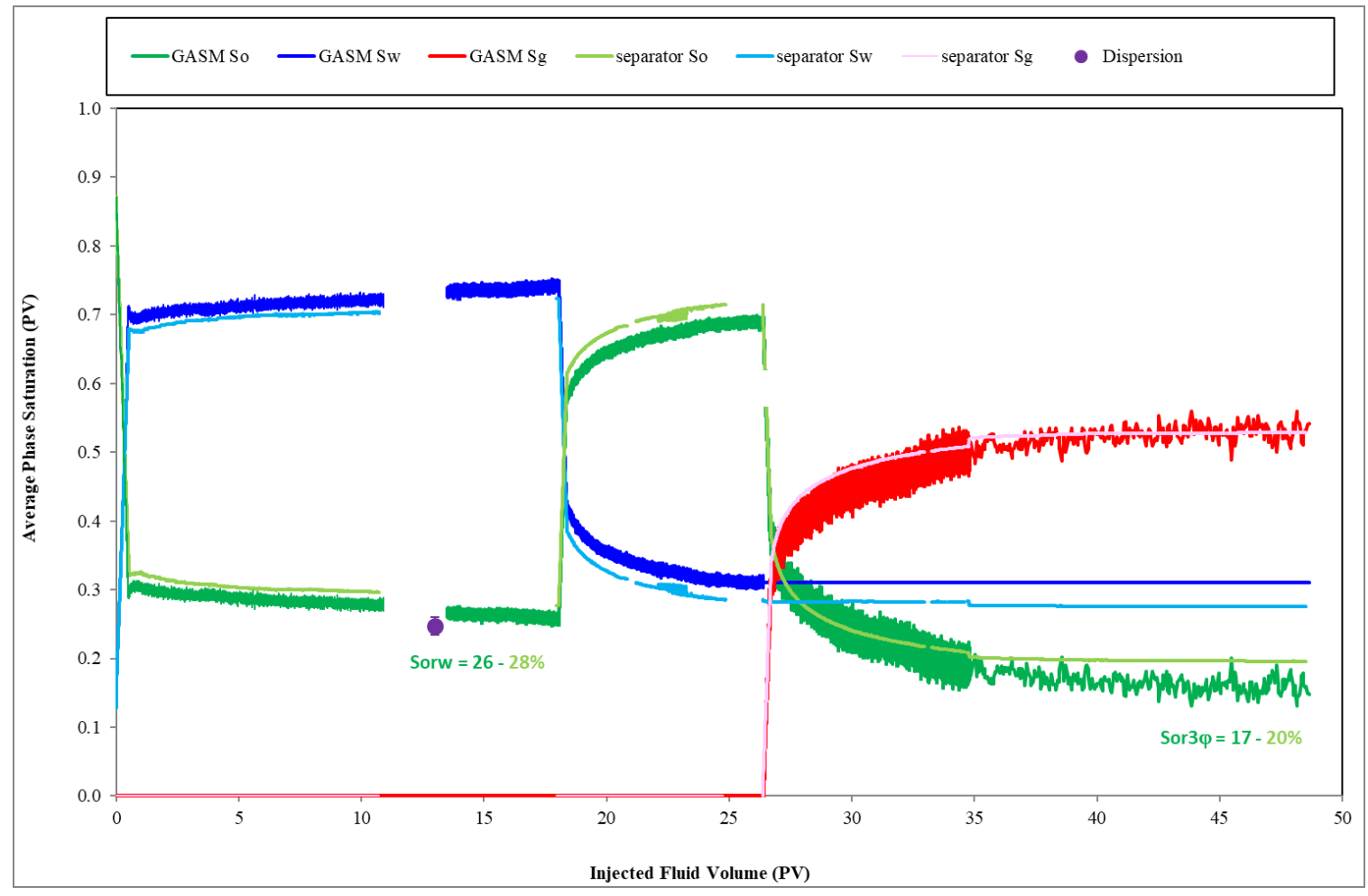

Figure 4. Saturations during coreflood test 1

The secondary waterflood shows a rapid drop in oil production after water breakthrough, whereas the following secondary drainage oil flood shows considerable water production after oil breakthrough. The data indicate intermediate wet or weakly water wet rock, consistent with previous wettability tests. The oil flood, 8PV at 4 $\mathrm{ml} / \mathrm{h}$, resulted in a remaining water saturation of $0.29-0.31 \mathrm{PV}$. The tertiary gas flood produced a significant amount of oil and negligible water, driving the remaining oil saturation to 0.17 or $0.20 \mathrm{PV}$, based on GASM or separator data, implying an Eps of $81 \%$.

\subsection{Coreflood 2 Results}

Results for Coreflood 2 are summarised in Table 2

Table 2. Summary of results for Coreflood 2

\begin{tabular}{|c|c|c|c|c|c|c|}
\hline Flood 2 & Equilibrium & Gas flood & Equilibrium Oil Flood & \multicolumn{3}{|c|}{ Water Flood } \\
\hline Swi (frac PV) & \multicolumn{6}{|c|}{0.121} \\
\hline PV Injected & \multicolumn{2}{|l|}{47} & 0.4 & \multicolumn{3}{|c|}{40} \\
\hline Flood Sequence & \begin{tabular}{|c|} 
Secondary \\
Gas Drainage \\
Sor (frac PV) \\
\end{tabular} & $\begin{array}{l}\text { Eps gravity } \\
\text { drainage }\end{array}$ & $\begin{array}{l}\text { Oil Flood Secondary } \\
\text { Imbibition Sgto (frac } \\
\text { PV) }\end{array}$ & $\begin{array}{c}\text { Tertiary water } \\
\text { flood Sgt } 3 \phi \\
\text { (frac PV) }\end{array}$ & $\begin{array}{c}\text { Tertiary Water } \\
\text { Flood Sor } 3 \phi, w \\
\text { (frac PV) }\end{array}$ & $\begin{array}{l}\text { Eps } \\
\text { tertiary } \\
\text { water }\end{array}$ \\
\hline $\begin{array}{c}\text { GASM } \\
\text { Separator }\end{array}$ & $\begin{array}{l}0.28 \\
0.31\end{array}$ & $68 \%$ & $\begin{array}{l}0.24 \\
0.22 \\
\end{array}$ & $\begin{array}{l}0.14 \\
0.12 \\
\end{array}$ & $\begin{array}{l}0.14 \\
0.21\end{array}$ & $84 \%$ \\
\hline
\end{tabular}


After the equilibrium gas flood rate had been increased to $400 \mathrm{ml} / \mathrm{h}$ and a total of $47 \mathrm{PV}$ has been injected, GASM saturation profiles indicated removal of oil retained by capillary forces close to the outlet at the end of the lowrate flood. Film drainage of the wetting oil phase (compared to the non-wetting gas phase) means that it is not possible to reach true residual saturation in a practical time-frame. However, the oil cut is very low, suggesting the remaining oil saturation of 0.28 or $0.31 \mathrm{PV}$ obtained from GASM or separator data respectively is representative of the saturation that could be achieved over a typical production timescale. The Eps is $68 \%$. Average phase saturations are shown in Figure 5. The secondary oil flood was terminated shortly after oil breakthrough and resulted in Sgto of 0.22 or $0.24 \mathrm{PV}$ based on separator or GASM data respectively. The maximum trapped gas saturation predicted by the Land [4] function is consistent with rocks of similar porosity. The mechanism for trapping of gas by oil is assumed to be snap-off of nonwetting gas by the invading oil phase.

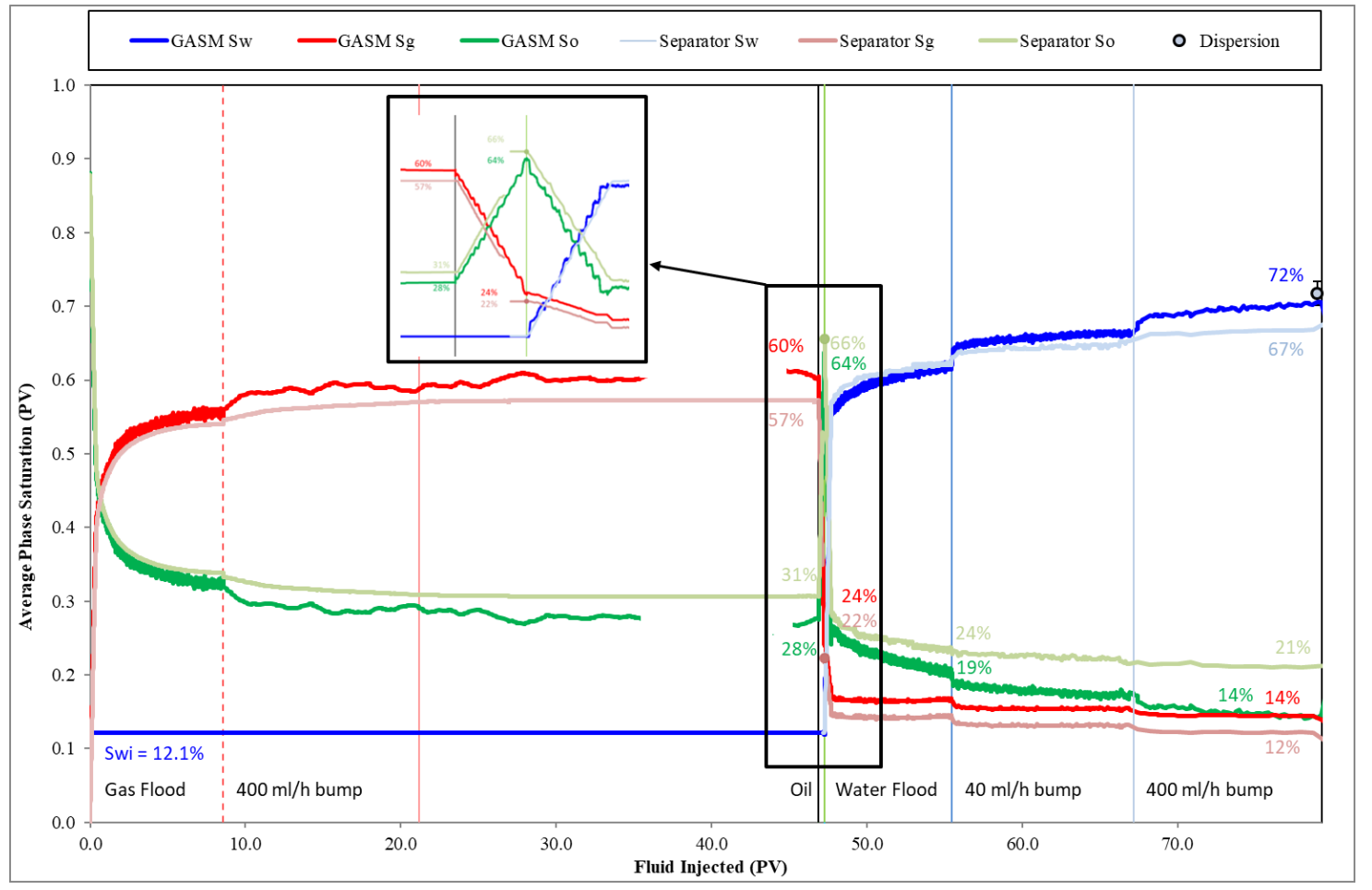

Figure 5. Saturations during Coreflood 2

The tertiary waterflood injected 40 PV in total and resulted in significant oil production, with a remaining oil saturation of 0.12 or 0.14 based on separator or GASM data, respectively, giving Eps $=84 \%$. A brine dispersion at Sor $3 \phi, \mathrm{w}$ indicated a brine saturation very similar to that inferred from GASM. At the start of the water flood, the separator recorded significant gas production, which virtually ceased after water breakthrough. This indicates production of gas that was trapped at the end of the preceding oil flood. The separator gas volume was used to calculate So and Sw from GASM LCR, as described earlier, and this explains why the average gas saturation calculated by GASM tracks the separator curve during the water flood. However, the average oil saturation calculated from separator data progressively deviates from the GASM value. It is hypothesised that slight dis-equilibrium between the oil and brine phases in the separator resulted in shrinkage of the produced oil in the separator, resulting in under- 
reporting of the true oil volume. The fact that the GASM-derived $\mathrm{Sw}$ agrees with the brine dispersion lends weight to this hypothesis, as do subsequent core floods (not reported here), which clearly showed oil shrinkage in the separator during the high-rate bump floods, where large volumes of brine were cycled through the separator.

\section{Discussion and Conclusions}

The coreflood data clearly demonstrate that, at a given throughput: (1) the secondary water flood (Coreflood 1) is more efficient at extracting oil than the secondary equilibrium gas flood (Coreflood 2); (2) the tertiary water flood at trapped gas (Experiment 2) is more efficient than the secondary water flood (Experiment 1); (3) the tertiary gas flood (Experiment 1) is more efficient than the secondary water and gas floods. The results are discussed in more detail in this section. The saturation data for the secondary gas flood in Coreflood 2 shows that the oil is draining very slowly, and consequently the secondary water flood recovers more oil at 18 PV throughput. A previous equilibrium gas coreflood on the same rock type showed a much lower remaining oil saturation at comparable throughput (c. 0.7 PV). However, this earlier coreflood was performed on a much higher permeability composite, and it is widely recognised that higher permeability rock typically shows higher recovery efficiency during equilibrium gas flooding [8]. An expression for Sor in the presence of trapped gas is given by Sor $=$ Sorw - a. Sgt. Our study indicates $\mathrm{a}=0.3-0.5$ based on GASM Sor $(0.14$ $\mathrm{PV})$, Sorw (0.21 PV) and Sgt $=0.24 \mathrm{PV}$ at the start of the water flood and Sgt $=0.14 \mathrm{PV}$ at the end. This value for a is broadly in agreement with values published in the literature [5] [6] [7] for intermediate to weakly water wet rocks and is consistent with competition for pore space between relatively non-wetting oil and gas phases. The tertiary gas flood in Coreflood 1 simulates a double displacement process, where waterflooding is followed by an equilibrium gas flood (with the addition of an intervening oil flood to simulate a mobilised oil bank). At the end of the tertiary gas flood, the remaining oil saturation is lower than that measured at the end of the secondary water flood. The mechanism for increased recovery by double displacement is oil spreading, which facilitates the connection of isolated drops of LCO by invading gas and subsequent drainage of the LCO film created [9] [10]. The production profile in this experiment demonstrates, however, that film drainage is a slow process, like the secondary gas flood in Coreflood 1. The tertiary water flood in Coreflood 2 produced approximately half of the gas trapped at the end of the preceding oil flood. Previous studies [5] have demonstrated that in strongly oil wet rock, tertiary waterflooding after gas flooding can lead to significant de-trapping of gas, of a similar order to that found in this study. Kralik et al. suggested that competition between non-wetting gas and brine phases causes de-trapping in strongly oil-wet rock. However, the rock used in this study appears to be intermediate to weakly water wet and other studies [8] [11] have shown that for intermediate wet rock, three phase Sgt is only slightly lower than for two phase Sgt.

Fluid analysis and recombination's were performed by Expro Fluid Analysis Centre in Reading, UK. The Authors are grateful to Alex Perriam, Tim Comer and Debra Wells at Expro for useful discussions.

\section{References}

[1] King, R.L., Stiles, J.H. Jr., and Waggoner, J.M. (1970). A Reservoir Study of the Hawkins Woodbine Field. SPE-2972-MS.

[2] Langenberg, M.A., Henry, D.M., and Chlebana, M.R. (1995). Performance and Expansion Plans for the Double-Displacement Process in the Hawkins Field Unit. SPE Res Eng 10 (4): 301-308. SPE-28603-PA

[3] Nicholls, C.I., Heaviside, J. (1998). GammaRay-Absorption Techniques Improve Analysis of Core Displacement Tests. SPE Formation Evaluation. SPE-14421-PA

[4] Land, C.S. (1968). Calculation of Imbibition Relative Permeability for Two- and ThreePhase Flow from Rock Properties. Trans. AIME, 243, 149-156

[5] Kralik, J.G. et al. (2000). Effect of Trapped Gas on Relative Permeability and Residual Oil Saturation in an Oil-wet Sandstone. SPE 62997.

[6] Holmgren, C.R. and Morse, R.A. (1951). Effect of Free Gas Saturation on Oil Recovery by Water Flooding, AIME Trans.192, 135. 
[7] Kyte, J.R., Stanclift, R.J. Jr, Stephan, S.C. Jr., and Rapoport, L.A. (1956). Mechanism of Water Flooding in the Presence of Free Gas, Pet. Trans. AIME 207, 215-221.

[8] Jerauld, G.R. (1997). General Three-phase Relative Permeability Model for Prudhoe Bay, SPE 36178

[9] Blunt, M.J. et al. (1994). What Determines Residual Oil Saturation in Three-phase Flow, SPE 27816.

[10] Chatzis, I et al. (1988). On the Investigation of Gravity-assisted Inert Gas Injection using Micromodels, Long Berea Sandstone Cores and Computer-assisted Tomography, SPE 18284.

[11] Jerauld, G.R. (1997). Prudhoe Bay Gas/Oil Relative Permeability, SPE 35718. 